\title{
FENOMENOLOGIA E EXPERIÊNCIA RELIGIOSA EM PAUL TILLICH
}

\author{
Paul Tillich's Phenomenology and Religious Experience \\ Fenomenología y Experiencia Religiosa en Paul Tillich
}

Tоммy AкIRA Goto

\begin{abstract}
Resumo: O objetivo deste artigo é explicitar a presença da fenomenologia filosófica no pensamento filosófico e teológico de Paul Tillich, tanto na questão metodológica quanto na investigação do fenômeno religioso. Apesar de Paul Tillich ter tido uma metodologia própria em sua teologia - tal como o método de correlação e do círculo teológico - também se encontra vários comentários sobre a fenomenologia em suas principais obras e a sua aplicabilidade na investigação da experiência religiosa. A fenomenologia que se afirma estar presente no pensamento de Tillich não é nem uma fenomenologia "pura" - de acordo com o conceito de Edmund Husserl, nem uma fenomenologia hermenêutica concebida por Martin Heidegger, apesar de ter sido influenciado por ambos os autores -, mas uma fenomenologia crítica, como sugerida pelo teólogo, que seria a união de ambos os elementos: 0 intuitivo-descritivo (fenomenologia clássica) e o crítico-existencial. Neste sentido, tem-se como ponto de partida da análise os comentários feitos por Tillich sobre a fenomenologia, entendendo o que o teólogo quis dizer sobre esta metodologia e destacando a relevância dessas observações para a construção de sua teologia e filosofia.
\end{abstract}

Palavras-chave: Fenomenologia; Experiência religiosa; Paul Tillich.

\begin{abstract}
The aim of this text is to point out the presence of the philosophical phenomenology in Paul Tillich's philosophical and theological thought, either concerning the methodological issue or the religious phenomenon investigation. In spite of Paul Tillich having had a methodology of his own in his theology - such as the correlation method and the theological circle - we can also find in his main works comments about phenomenology and its applicability in the investigation of the religious experience. The phenomenology that we assert to be present in Tillich's thought is neither a "pure" phenomenology - according to Edmund Husserl's concept nor a hermeneutic phenomenology inspired by Martin Heidegger, in spite of having been influenced by both authors -, but a critical phenomenology, as suggested by the theologian, that would be the union of both elements: the intuitive-descriptive (phenomenology classical) and the critical-existencial. In this sense, we shall start from the comments made by Tillich on phenomenology, understanding what he meant about this methodology and emphasizing the relevance of those comments for the construction of his theology and philosophy.
\end{abstract}

Keywords: Phenomenology; Religious experience; Paul Tillich.

Resumen: Este texto tiene como objetivo mostrar la presencia de la fenomenología filosófica en el pensamiento filosófico y teológico de Paul Tillich, sea en la cuestión metodológica, sea en la investigación del fenómeno religioso. A pesar de Paul Tillich haber tenido una metodología propia en su teología - como el método de la correlación y el círculo teológico - también puede encontrar, en sus obras principales, comentarios sobre la fenomenología y su aplicabilidad en la investigación de la experiencia religiosa. La fenomenología que afirma estar presente en el pensamiento de Tillich, no es una fenomenología "pura" en el sentido de Edmund Husserl y tampoco una fenomenología hermenéutica inspirada en Martin Heidegger - aunque fue influenciada por ambos autores - sino una fenomenología crítica, como lo ha sugerido el propio teólogo, que sería la unión del elementos: el intuitivo-descriptivo (fenomenología clásica) con el existencial-crítico. En este sentido, tienes como punto de partida los comentarios hechos por Tillich sobre la fenomenología entendiendo lo que quiso decir sobre esa metodología y destacando la relevancia de estos comentarios para la construcción de su teología y filosofía.

Palabras-clave: Fenomenología; Experiencia religiosa; Paul Tillich.

\section{Introdução}

O objetivo deste artigo é explicitar a influência da Fenomenologia de Edmund Husserl (1849-1938) e Martin Heidegger (1889-1976) no empreendimento filosófico e teológico de Paul Tillich (1886-1965). De início destacarse-á como Tillich compreendeu a Fenomenologia e a relacionou à teologia e filosofia da religião para, em seguida, indicar como o filósofo apropriou-se do método fenomenológico em seus conceitos. É importante destacar, logo de início, que não há em Tillich uma descrição explícita do método fenomenológico em suas análises teológicas e filosóficas. Por isso é preciso, a partir dos breves comentários do próprio autor, entender o que quis dizer sobre a Fenomenologia e sua apropriação.

O que se pode destacar é a evidente presença da Fenomenologia no pensamento filosófico e teológico de Tillich. Essa fenomenologia deve ser compreendida de modo particular, não podendo ser generalizada como o principal método teológico ou filosófico do teólogo. 
Entretanto, a analítica fenomenológica está presente nas pesquisas do autor e percorre de modo ora implícito, ora explícito em suas obras.

A partir de leituras atentas e estudos, chegou-se à conclusão de que a Fenomenologia, que se apresenta de modo particular, está presente em Tillich nos seguintes aspectos: a) a Fenomenologia é legitimada como um método filosófico para filosofia da religião e teologia (citado, por exemplo, no texto "Filosofia da Religião"); b) a Fenomenologia é postulada como um recurso metodológico para analisar os conceitos básicos da teologia, principalmente experiência religiosa; e c) a Fenomenologia como ontologia, ou seja, a ontologia tillichiana como fenomenológica.

Apesar de Paul Tillich ter desenvolvido uma metodologia própria - como o método da correlação - pode-se reconhecer outra metodologia aplicada na sua analítica. Essa outra metodologia é a Fenomenologia. Encontra-se em suas obras principais citações e definições que se referem à fenomenologia, por exemplo, Tillich (1951/2001) em seu texto sobre Razão e Revelação sugeriu uma fenomenologia crítica para a teologia em vista da análise de seus conceitos básicos.

Reforçando essa análise crítica, o conceituado historiador da Fenomenologia Herbert Spiegelberg (1965) comentou em sua obra monumental O Movimento Fenomenológico, a relação de Paul Tillich com a Fenomenologia, relação essa marcada por duas fases. O autor diz:

Na teologia americana, a fenomenologia recebeu importante apoio do recente recurso de Paul Tillich ao método fenomenológico. Todo este caminho ainda é notável, pois durante a sua carreira alemã, Tillich rejeitou o método fenomenológico e junto com isso o pragmatismo a favor de uma aproximação "críticadialética”. A principal objeção dele na ocasião era o caráter não-histórico e antiexistencial da fenomenologia. Há indicações que, em grande parte, com o advento da versão de Heidegger da fenomenologia, Tillich mudou a sua atitude. De fato, ele parece agora considerar a fenomenologia como método primário de filosofia existencial. O mais importante agora é que ele afirma, na sua Teologia Sistemática, a necessidade do método fenomenológico na concepção de Husserl das Idéias, como essencial para a teologia. (Spiegelberg, 1965, p. 639)

Esses aspectos que se destacam entre Paul Tillich e a fenomenologia husserliana mostram definitivamente a interdependência entre a filosofia e a teologia no pensamento do autor analisado. Essa interdependência se confirma no primeiro aspecto citado, na qual Tillich legitima a fenomenologia de Husserl, principalmente a redução eidética como método filosófico para a filosofia da religião.

Em relação ao primeiro aspecto tem-se, por exemplo, o trabalho Filosofia da Religião (1969/1973), na qual
Tillich expõe quatro métodos possíveis da filosofia da religião se fundamentar: crítico-dialético, fenomenológico, pragmático e o "metalógico”. Neste texto o teólogo reconheceu a importância do método fenomenológico e a destacou como um método para a filosofia da religião se aproximar de seu objeto de forma mais vital, assim legitimando-a como um recurso metodológico para a filosofia da religião. No texto, analisa Tillich que:

Segundo o método fenomenológico, a filosofia da religião, portanto, será capaz de intuir eideticamente a essência e as qualidades peculiares da religião em qualquer manifestação religiosa. Tal intuição será independente da realidade empírica do objeto e possuirá, contudo, um apriori de rico conteúdo não meramente formal. (Tillich, 1969/1973, p. 29)

Ao mesmo tempo, também explicitou o fato da fenomenologia não abranger o movimento individual-histórico, pela fenomenologia pura iniciar sua investigação a partir das experiências vivências em visando às essências ou do universal. Na acepção de Tillich (1951/2001), o fenomenólogo responderá sobre um evento revelatório típico a partir de seu sentido universal. Assim, para o teólogo a fenomenologia pura embora seja competente na área das significações lógicas, é relativamente competente no âmbito das realidades espirituais.

Para Tillich a vida espiritual, experienciada, cria mais que significações exemplares e universais; ela cria "corporificações únicas de algo universal”. Para a apreensão dessas "corporificações únicas", Tillich sugeriu, então, uma fenomenologia crítica: "Trata-se de uma fenomenologia crítica, que une um elemento intuitivo-descritivo com o elemento existencial-crítico" (Tillich, 1951/2001, p. 121), preservando a abordagem fenomenológica.

A fenomenologia crítica é um método que mantem o elemento intuitivo-descritivo da fenomenologia pura com a técnica de descrever o sentido daquilo que se manifesta, porém acrescenta-se à análise o elemento existencial-crítico, ou seja, o caráter concreto, histórico e único daquilo que se manifesta. Com isso conclui Tillich:

A primeira forma, porem, leva ao método de abstração, que priva os exemplos de sua concretude e reduz seu significado a uma generalidade vazia (p.ex., uma revelação que não é nem judaica nem cristã, nem profética nem mística). É precisamente isso que a fenomenologia deseja superar. A segunda forma está baseada na convicção de que uma revelação especial (p.ex., a aceitação de Jesus como o Cristo por Pedro) é a revelação final e, em conseqüência, é universalmente válida. (...) A fenomenologia crítica é o método mais adequado para fornecer uma descrição normativa dos significados espirituais (e também Espirituais). (Tillich, 1951/2001, p. 120-121) 
O segundo aspecto está relacionado com a aceitação e validação da Fenomenologia como recurso metodológico na teologia. O interesse da teologia em utilizar a Fenomenologia deu-se em Tillich, fundamentalmente como recurso metodológico para rever e avaliar conceitos postulados da sua própria analítica. Não tem só a intenção de buscar a essência do religioso no sentido universal e histórico - como no caso da história das religiões - mas de fundamentar rigorosamente aquilo que já foi dado pela revelação a partir da experiência. Explica Tillich, no capítulo sobre "A realidade da revelação" que a:

finalidade do método fenomenológico é descrever 'significados', deixando de lado, por um tempo, a questão da realidade [existência fática] á qual se referem. (...) A teologia deve aplicar a abrdagem fenomenológica a todos os conceitos básicos, forçando assim seus críticos a ver sobretudo o que significam os conceitos criticados e obrigando a si próprio a fazer descrições cuidadosas de seus conceitos e a usá-los com consistência lógica, evitando assim o perigo de tentar preencher as lacunas lógicas com material devocional (Tillich, 1951/2001, p. 120).

É importante salientar que existe uma diferença entre a fenomenologia religiosa e a teologia, porque para a teologia há uma impossibilidade da universalização da experiência religiosa dada pela revelação. Isso significa que cada revelação tem um caráter concreto e pessoal que o universal e o abstrato não abrangem. Esta crítica visa esclarecer que a teologia tillichiana, mesmo aplicando a fenomenologia, não pode ser confundida e nem se assemelhar com a fenomenologia da religião.

Pode-se dizer, então, que Paul Tillich foi um precursor no esclarecimento destas diferenças, mesmo que de maneira implícita, já que formulou esta crítica em seus próprios estudos. Assim, é devido salientar que existe uma diferença em se utilizar metodologicamente a fenomenologia na teologia e de concebê-la como fenomenologia da religião. O caminho da fenomenologia filosófica, de sua contribuição como fenomenologia da religião e de ser um recurso metodológico das ciências da religião, faz-se necessário para compreendermos a influência da fenomenologia em Paul Tillich. Por fim, o último aspecto a ser destacado é a aproximação e a semelhança da Fenomenologia com a teologia de Tillich no âmbito da ontologia. Sem dúvida, é na ontologia tillichiana que a fenomenologia se fez presente como método e atitude.

A partir destes esclarecimentos iniciais sobre a compreensão de Tillich da Fenomenologia, pode-se indicar os possíveis encontros metodológicos do teólogo com o método. A Fenomenologia tem primeiramente o caráter de ser uma epistemologia, ou seja, de analisar a experiência religiosa a partir dela mesmo. Sabe-se que muitos conceituam a experiência religiosa com conceitos e idéias pautados em ideologias ou conceitos filosóficos. A pro- posta fenomenológica está um buscar um "começo bom”, ou seja, encontrar a gênese da experiência religiosa por ela mesma. Explica Tillich:

O teste de uma descrição fenomenológica consiste em sua capacidade de oferecer um quadro que seja convincente, de torná-lo visível a qualquer pessoa que esteja disposta a olhar na mesma direção, de iluminar com ele outras idéias e de tornar compreensível a realidade que estas idéias pretendem refletir. A fenomenologia é uma forma de considerar os fenômenos tal como 'se apresentam', sem interferência de pré-conceitos e explicações negativas ou positivas (Tillich, 1951/2001, p. 120).

Dito isso, é possível resumir rapidamente o método fenomenológico de E. Husserl nos seguintes aspectos: um método analítico-descritivo (busca o significado a partir do próprio fenômeno, sem conduzir a teorias metafísicas); uma ciência eidética (busca a essência do fenômeno); conduz à certeza (evidência racional), sendo assim uma disciplina a priori; e fundamentalmente é um método derivado de uma atitude, pois se presume ser sem pressupostos ("Voltar às coisas mesmas"). Dessa breve caracterização, destaca-se o que Husserl comentou em sua Introdução da obra Idéias para uma Fenomenologia Pura e para uma filosofia fenomenológica (1913): a fenomenologia possibilita "aprender a se mover livremente nela, sem nenhuma recaída nas velhas maneiras de orientar-se, aprender a ver, diferenciar, descrever o que está diante dos olhos, exige, ademais, estudos próprios e laboriosos”. (Husserl, 1913/2006, p. 27).

Em Husserl, a Fenomenologia caminhou também na ontologia, porque tinha o objetivo de encontrar o fundamento das ciências e, para isso foi necessário ampliar o método para que se levasse à análise ao originário do ser. Ao se caminhar rumo à origem do ser, penetra-se necessariamente no âmbito do ser. $\mathrm{O}$ fundamento dos conceitos está naquilo que não varia, ou seja, no invariável, o que permanece. Segundo a concepção de Husserl (1913/2006), o invariável é a essência do ser, aquilo que permanece e, por isso o invariável passa a ser entendido como essência ontológica. Dessa forma:

não é no âmbito das ciências de fatos ou experimentais, mas exclusivamente no âmbito das ciências eidéticas, que Husserl fala de 'ontologias' e 'ontologia'. O caráter hierárquico que aqui se manifesta leva-nos a dois grandes grupos, o primeiro das quais determina as 'ontologias regionais'; o segundo, a 'ontologia formal'. (Fragata, 1965, p. 23)

Assim, evidencia-se a questão do ser originariamente como uma questão fenomenológica, porque "a fenomenologia é concebida como uma ontologia a partir das condições a priori dos objetos e em seu conteúdo categorial. 
A ontologia husserliana se preocupa em revelar as estruturas internas do mundo e seus domínios como indicadores do ser" (Josgrilberg, 2001, p. 164).

Para a teologia tillichiana, esses aspectos metodológicos da Fenomenologia de Husserl foram tratados com atenção, pois Tillich encontrou neles a garantia de poder rever e validar os conceitos já concebidos pela filosofia e teologia. Para Tillich (2001) a Fenomenologia propicia a compreensão do sentido originário dos fenômenos, indo diretamente a eles pela intuição originária, saindo das abstrações metafísicas dos conceitos chegando à evidência. Rever os conceitos teológicos pela Fenomenologia é dá-los o caráter de certeza. Nesse sentido, o caminho que Tillich elege para a análise da experiência religiosa será o caminho do sentido originário do ser, ou seja, para além dos processos lógicos e da análise da consciência. Percebe-se aqui uma análise se desenvolveu como ontologia, ou seja, a partir de uma "razão ontológica".

Além da Fenomenologia se constituir como um método ou uma ciência de rigor, também se constituiu como ontologia, principalmente à partir da contribuição de Martin Heidegger. Com Heidegger, a Fenomenologia e a Ontologia (Fenomenologia Hermenêutica) se tornaram um único meto do de investigação e o objetivo de toda a filosofia. Porque a ontologia para resgatar o sentido primeiro do ser só é possível, então, como fenomenologia. Isso é fortemente evidenciado na § 7 da obra Ser e Tempo (Heidegger, 1927/1993) na qual comenta:

Ontologia e fenomenologia não são duas disciplinas diferentes da filosofia ao lado de outras. Ambas caracterizam a própria filosofia em seu objeto e em seu modo de tratar. A filosofia é uma ontologia fenomenológica e universal que parte da hermenêutica do dasein, a qual, enquanto analítica da existência, amarra o fio de todo questionamento filosófico no lugar de onde ele brota e para onde retorna. (Heidegger, 1927/1993, p. 69)

Com a publicação de Ser e Tempo, a filosofia colocouse paradigmática devido à desconstrução da onto-teometafísica e da primazia das ciências empíricas. Para Heidegger, a ontologia deve se constituir como uma ontologia fundamental, ou seja, deve-se voltar às coisas mesmas e ir diretamente a questão do ser sem passar pelas especulações anteriores. Para isso o resgate da questão do ser deve ser colocado, fundamentalmente, pela pergunta do sentido do ser. Comenta Heidegger que: "Devese efetuar essa destruição seguindo o fio condutor da questão do ser até se chegar às experiências originárias em que foram obtidas as primeiras determinações do ser que, desde então, tornaram-se decisivas" (Heidegger, 1927/1993, p. 50).

A teologia européia não poderia deixar de ser influenciada diretamente por esta mudança ontológica com o advento do método fenomenológico-hermenêutico de Heidegger, tais como a teologia de Rudolf Bultmann ou de Hans Jonas. Algumas teologias contemporâneas e posteriores à Fenomenologia de Husserl e Heidegger, sofreram também revisões epistemológicas e ontológicas, seja no aspecto da aceitação ou negação, tais como as teologias de Gianni Vattimo, Jean Luc-Marion, Jean- Louis Chrétien e Jean-Yves Lacoste.

É notório destacar que também por este motivo, a fenomenologia influenciou, além das teologias às ciências da religião. Essa influência fenomenológica às ciências religiosas se mostrou basicamente de duas maneiras, como estabelecem Filoramo \& Prandi (1999): uma, estruturando-se como uma disciplina particular, denominada Fenomenologia da Religião; e outra, como recurso metodológico para outras disciplinas, filosofia, psicologia, antropologia, história ou como no caso: a teologia.

Mas, ainda é importante comentar que existe uma diferença em se utilizar à fenomenologia na teologia e ser uma fenomenologia teológica. A teologia fenomenológica se diferencia da teologia - mesmo quando essa se utiliza da fenomenologia como método - porque põe "entre parênteses" a questão da prova ou não da existência de Deus. A teologia fenomenológica, como define Maldonado (2003), busca o descobrimento de todo o sentido da transcendência que se origina na vivência, ou seja, no campo das vivências.

Voltando a teologia tillichiana, diga-se que se define fundamentalmente pelo método de correlação e não pela fenomenologia. Entretanto, a fenomenologia auxiliou a correlação no sentido validar os conceitos polares que são correlacionados. A fenomenologia precedeu a correlação na análise ontológica, ou seja, ela está presente na análise existencial. Os conceitos correlacionados são fundamentalmente ontológicos e para a descrição rigorosa desta ontologia Tillich fez buscou uma fundamentação fenomenológica. Tem-se em algumas obras a Fenomenologia na fundamentação da análise ontológica e do método de correlação, definindo estruturalmente a teologia. Somente pela fenomenologia não se tem uma teologia tillichiana, mas é a partir da correlação que a teologia se fez presente, principalmente na correlação do ser e Deus.

A Fenomenologia dada antecipadamente à correlação se mostrou de forma ontológica. Para atingir o fundamento do ser, a compreensão fenomenológica se apresentou como melhor método, por buscar diretamente o fenômeno naquilo que se manifesta, sem rodeios metafísicos ou especulativos. Essa ontologia presente na correlação surgiu como fenomenológica. Goto (2004) destaca, então, três características da ontologia tillichiana como fenomenológica: a) a primazia do retorno ao originário (sentido originário do ser-essências); b) a estruturação de categorias ontológicas (categorias existenciárias e não metafísicas); e c) o fato de a análise ontológica só ser possível como descritiva (pela experiência).

Essas são as semelhanças que mais caracterizam a ontologia tillichiana como uma ontologia fenomenológi- 
ca. Contudo, ainda como defende Goto (2004), a análise ontológica tillichiana busca as significações originárias na correlação, estruturando-se em quatro níveis: 1) a estrutura ontológica básica; 2) os elementos que constituem a estrutura básica; c) as características do ser (condições da existência) e, por fim: 4) as categorias do ser e conhecer.

Diante dessas apropriações é importante salientar que a fenomenologia husserliana não descartou a pólo existencial, apenas evitou a palavra "existência", como enfatiza Fragata (1965), para que não houvesse uma confusão entre a existência fática e a própria atitude natural. Ainda, para Husserl a existência e a essência estão correlacionadas, sem que uma deixe de apreender a outra. Pode-se postular a tese que Heidegger entendeu e seguiu esse caminho e, por isso, elegeu a fenomenologia como método de sua ontologia.

Para explicitar o pensamento filosófico e teológico de Paul Tillich como fenomenológico, elegeu-se três obras que evidenciam a presença desta metodologia nos pontos que foram definidos como características fenomenológicas. São elas: Teologia Sistemática (1951/2001), A Coragem de ser (1952/1973) e Amor, Poder e Justiça (1954/1970), e em cada uma delas aponta-se resumidamente características fenomenológicas.

Na Teologia Sistemática (1951/2001), como citado anteriormente, a Fenomenologia foi abordada como um método complementar ao método da correlação na construção de uma teologia sistemática. Esta característica não aparece explicitamente, porque como colocado anteriormente, Tillich tem como método teológico principal o "método da correlação", sendo sua sistemática construída fundamentalmente da correlação entre a questão existencial e a resposta teológica. "A teologia sistemática usa o método de correlação. [...] O método de correlação explica os conteúdos da fé cristã através de perguntas existenciais e de respostas teológicas, em interdependência mútua" (Tillich, 1951/2001, p. 58).

Entretanto, além da questão metodológica acima analisada, a fenomenologia está presente também na análise ontológica, implícita na correlação. É na análise existencial que a fenomenologia aparece, para garantir o rigor dos conceitos que formam os pólos da correlação. O pólo fenomenológico é o pólo existencial (perguntas), justamente por ser dado pela experiência da compreensão do ser. "A análise da existência, inclusive o desenvolvimento das perguntas implícitas na existência, é tarefa filosófica [...]". (Tillich, 1951/2001 p. 60).

No entanto, perguntas e respostas estão correlacionadas, logo não se pode separá-las fenomenologicamente e, para isso Tillich propõe uma outra versão fenomenológica, isto é, uma fenomenologia crítica. A fenomenologia crítica é permitida, desde a fenomenologia enquanto método se tornou uma possibilidade de pensamento. Tillich postulou a fenomenologia crítica, como uma fenomenologia que tem o elemento existen- cial-crítico, ou seja, a descrição do caráter concreto único da experiência. Assim, temos na Teologia Sistemática a presença antecedente da fenomenologia, como fenomenologia crítica.

A Coragem de ser (1952/1973) é a obra na qual Tillich se mostra mais fenomenológico. Isso porque a fenomenologia está no âmbito de sua ontologia, que difere da fenomenologia crítica da sistemática. Nesta obra, evidencia-se a análise da angústia por ver nela o modo de análise fenomenológico. Tillich analisou a angústia assemelhando-se com os critérios da ontologia fenomenológica de Heidegger, que viu nesta ontologia fundamental a única possibilidade de encontrar o sentido originário do ser. Foi na ontologia da angústia que Tillich mostrou sua análise ontológica como análise fenomenológica.

Nessa obra é analisado a influencia da fenomenologia-hermenêutica de M. Heidegger na qual se percebe que Tillich a reproduziu metodologicamente como um recurso analítico. Ao mesmo tempo, cabe advertir que a análise ontológica da angústia que Tillich descreveu se afasta da ontologia heideggeriana de Ser e Tempo. Isso acontece porque Tillich propõe a superação da angústia pela coragem de ser do ponto de vista teológico ficar restrito à facticidade da existência e no niilismo heideggeriano do ser-para-a-morte. Nesse sentido, para Tillich, "a coragem de ser é uma expressão de fé, o que a 'fé’ significa deve ser entendido através da coragem de ser”. (Tillich, 1952/1973, p. 134).

Tem-se aqui uma fenomenologia do ser, exposto por sua coragem de ser. Essa análise fenomenológica buscou o retorno ao originário da coragem a partir da descrição dos elementos constitutivos de ser, destacando assim seus pólos correlacionais dos modos de ser: os tipos de angústia e a coragem de ser. Por isso, pode-se também falar em uma fenomenologia da angústia; uma fenomenologia que talvez tenha faltado na ontologia fenomenológica de Martin Heidegger.

A obra Amor, Poder e Justiça - Análise ontológica e implicações éticas (1954/1970) representa outro exemplo da fenomenologia-hermenêutica na análise ontológica do teólogo. Nessa obra tem-se a ontologia do amor como uma fenomenologia do amor, pois nela o teólogo buscou a primazia do sentido do amor, evitando as ciladas, os problemas e os maltratos que a palavra "amor" esteve sujeita. Com isso Tillich descreveu fenomenologicamente o amor a partir de sua natureza (origem) ontológica, porque só assim poderia resgatar o seu sentido originário (ser amor) ao descrever as diferentes formas de amar, a partir da experiência.

Isso é percebido logo no Prefácio da obra na qual Tillich afirma: "A ontologia precede toda outra tentativa de aproximação cognitiva a realidade. (...) Ninguém pode fugir da ontologia se quiser conhecer. Já que conhecer significa reconhecer alguma coisa como ser". (Tillich, 1954/1970, p. 32-33). Na análise fenomenológica do amor, 
percebe-se como Tillich conheceu o ser humano, ou seja, a partir da descrição e compreensão do ser e, não de conceitos e teorias.

O amor é um conceito ontológico, deve ser analisado pela fenomenologia-hermenêutica, ou seja, deve-se começar pela pergunta: o que significa o amor (ser)? Nisso, destaca Tillich, evitam-se muitas ciladas em ética social, teoria política e educação pela incompreensão do caráter ontológico do amor. Em suas análises descritivas, Tillich conclui que o "amor é unir o que está separado. A reunião pressupõe separação daquilo que estava essencialmente junto. (...) Portanto, o amor não pode ser descrito como a união do estranho, mas como a reunião do separado". (Tillich, 1954/1970, p. 36). Como analisa Goto (2004), para o teólogo toda a vivência amorosa, seja emotiva ou ética, está fundada originalmente em uma vivência do ser doadora de sentido.

É importante advertir que nessa obra Tillich ainda promove a fenomenologia do poder e da justiça, pois esses estariam ligados ao fenômeno do amor. Os mesmos problemas e confusões na análise do amor estão em relação com o poder e com a justiça, por isso todos eles devem ser levados a uma análise ontológica do tipo fenomenológica.

\section{Considerações Finais}

A partir desta análise pode-se dizer que o filósofo e teólogo Paul Tillich promoveu em algumas obras, a Fenomenologia como recurso metodológico em suas análises teológicas e filosóficas. Ainda, podemos afirmar como foi evidenciado nessa crítica que Tillich conheceu o método fenomenológico e reconheceu a importância dele como um método descritivo das essências por mantém, fundamentalmente, o rigor daquilo que pretende investigar.

No entanto, ainda é preciso analisar a relação do histórico da fenomenologia com as leituras de Tillich, isto é, reconhecer e mapear com maior precisão quais foram os textos que Tillich fez da Fenomenologia de Husserl, Heidegger ou outro filósofo fenomenólogo para entender alguns aspectos de sua crítica.

Paul Tillich foi um dos pioneiros ao incluir o método fenomenológico na teologia, não de forma sistemática, porém dialogando criticamente com ela. Disso concluise que Tillich não foi fenomenólogo da religião e nem um teólogo fenomenológico, segundo a análise, mas recorreu a Fenomenologia como recurso metodológico nas situações que só ela poderia ser eficaz, como é o caso da razão e do ser.

\section{Referências}

Filoramo, G. \& Prandi, C. (1999). As ciências das religiões. São Paulo: Paulus.

Fragata, J. (1965). O conceito de ontologia em Husserl. Em Julio Fragata (Org.). Perspectivas da fenomenologia de Husserl [pp. 17-43]. Coimbra: Centro de Estudos Fenomenológicos.

Goto, T.A. (2004). O Fenômeno Religioso - A Fenomenologia em Paul Tillich. São Paulo: Paulus.

Heidegger, M. (1993). Ser e Tempo. Petrópolis: Vozes (Original publicado em 1927).

Husserl, E. (2006). Idéias para uma Fenomenologia Pura e para uma filosofia fenomenológica. Aparecida: Idéias \& Letras (Original publicado em 1913).

Josgrilberg, R.S. (2001). Husserl: as Investigações Lógicas - o projeto transcendental e a ontologia. Em Ricardo Timm de Souza (Org.). Fenomenologia Hoje - Existência, ser e sentido no alvorecer do século XX [pp. 159-177]. Porto Alegre: EDIPUCRS.

Maldonado, C. E. (2003) Significado espiritual de la filosofía fenomenológica. Em: Actas del IX Congreso Internacional de Filosofía Latinoamericana. Desafíos de la religión en la época del multiculturalismo y la globalización. [págs. 183193]. Bogotá: Universidade Santo Tomás.

Spiegelberg, H. (1965). The Phenomenological Movement - a historical introduction. Netherlands: Martinus Nijhoff/ The Hague.

Tillich, P. (1976). A Coragem de Ser. Rio de Janeiro: Paz e Terra (Original publicado em 1952).

Tillich, P. (1970). Amor, Poder y Justicia - Análisis ontológicos y aplicaciones éticas. España: Ediciones Ariel (Original publicado em 1954).

Tillich, P. (1973). Filosofia de la Religion. Buenos Aires: Megápolis (Original publicado em 1969).

Tillich, P. (2001). Teologia Sistemática. São Paulo/São Leopoldo: Paulinas/Sinodal (Original publicado em 1951).

Tommy Akira Goto - Doutor em Psicologia pela PUC-Campinas, Mestre em Ciências da Religião pela Universidade Metodista de São Paulo, Professor Adjunto I da Universidade Federal de Uberlândia. Endereço Institucional: Universidade Federal de Uberlândia, Faculdade de Artes, Filosofia e Ciências Sociais, Faculdade de Psicologia. Av. Pará, 1720, Bairro Umuarama. CEP 38400-902, Uberlândia (MG). E-mail: tommy@ipsi.ufu.br

Recebido em 28.08.11 Aceito em 30.11.11 